\title{
The Effectiveness of Antiviral Therapy in Patients with Hyperplastic Processes of the Endometrium of Child bearing Age
}

\author{
Tetiana Vereshchahina $^{1^{*}(\mathrm{D})}$, Alla Boychuk ${ }^{2 *(D)}$ Victor Sopel $^{3(D)}$ Bohdan Behosh $^{4(D)}$, \\ Bohdan Onyskiv 5 (iD
}

1 Department of Obstetrics and Gynaecology, Institute of Postgraduate Education I. Ya. Horbachevsky Terniopil National Medical University, Ternopil, Ukraine; e-mail: Tania7777Tania@ukr.net; (T.V); boychuk_alla@tdmu.edu.ua; (A.B.); sopelv@tdmu.edu.ua; (V.S); behosh@tdmu.edu.ua; (B.B); onyskiv@tdmu.edu.ua; (B.O.);

* Correspondence: Tania7777Tania@ukr.net (T.V.); boychuk_alla@tdmu.edu.ua (A.B.);

Scopus Author ID 6603457364

Received: 18.07.2020; Revised: 10.08.2020; Accepted: 11.08.2020; Published: 15.08.2020

\begin{abstract}
Despite the emergence of new directions in the treatment of patients with hyperplastic processes of the endometrium, the problems of treatment of this pathology remain one of the most pressing issues in gynecology and still not the final solution. Therefore, the aim of our study was to test the effectiveness of antiviral therapy as an antirelapse treatment of hyperplastic processes of the endometrium (HPE) in women of reproductive age. Patients with hyperplastic processes of the endometrium (60) who sought medical help in the gynecological department were examined and treated depending on the method of treatment after the data were obtained through morphological examination. The obtained data demonstrate a fairly high efficiency of the selected treatment and diagnostic algorithm. The recurrence rate of acyclovir in women with HPE is $-16.67 \%$, which is significantly (p $\& 1 t ; 0.05)$ lower than in women who received traditional therapy - 40\%. Additional use of antiviral therapy in the complex treatment of GPP prevents recurrence of the disease and significantly increases treatment by 2.40 times. The results of the study substantiate the need to include antiviral therapy as a pathogenetically justified therapy for patients with hyperplastic endometrial processes.
\end{abstract}

Keywords: hyperplastic processes of the endometrium; viral lesions of theendometrium; antiviral therapy.

(c) 2020 by the authors. This article is an open-access article distributed under the terms and conditions of the Creative Commons Attribution (CC BY) license (https://creativecommons.org/licenses/by/4.0/).

\section{Introduction}

Endometrial hyperplasia is a disease of the uterus, which is manifested by changes in the glands and stroma of the endometrium. This is the main form of hyperproliferative diseases of the mucous membrane of the uterus and the most common benign pathology of the uterus in women of different ages [1-3].

Timely diagnosis and treatment of this pathology are some of the urgent problems of modern gynecology. The high frequency of recurrences of hyperplastic processes of the endometrium, the possibility of their malignant transformation, requires improvement of methods for diagnosing this pathology, rethinking the experience [4-7].

With the development of modern medicine, diagnostic techniques are constantly being improved. For the timely detection of the hyperplastic process, its correct clinical interpretation, the establishment of hormone dependence of the hyperplastic process, and 
adequate differentiated treatment, it is important to stage and apply modern highly informative techniques [8-10].

In the regulation of tissue homeostasis and the pathogenesis of proliferative diseases, an important role belongs not only to the strengthening of cell proliferation but also to the violation of the regulation of cell death. The resistance of endometrial cells to apoptosis leads to the accumulation of altered and excessively proliferating cells. This is a characteristic feature of nonplastic changes of the endometrium [11-14].

A number of authors consider HPE as a clinical and morphological syndrome caused by damage to the endometrium by infectious agents, with numerous secondary morphological and functional changes that disrupt cyclic biotransformation and susceptibility of the uterine mucosa [15-17].

Scientific publications on this problem allowed us to analyze some etiopathogenetic pathways in the formation of hyperplastic changes in endometrial tissue, in particular, to assess the role of infectious factors as a provoking and etiological factor in the occurrence of HPE [18-20].

Despite the emergence of new directions in the management of patients with hyperplastic processes of the endometrium, the problems of treatment of this pathology remain one of the most pressing issues in gynecology, and still far from a final solution. This is primarily due to the complex and heterogeneous patho- and morphogenesis of the disease, which may depend on many factors, as well as manifested by the individual sensitivity of the organism to various therapeutic effects [21, 22, 28, 29].

The study of research results, in our opinion, indicates the feasibility of further study of the role of viral infection as an etiopathogenetic factor in the occurrence of HPE, as well as the study of the spectrum of viral infection and the role of individual viruses in the occurrence and recurrence of HPE. The study of these features will expand the possibilities of predicting the course and prospects of preventive treatment of relapses in HPE.

The aim of our study was to test the effectiveness of antiviral therapy as an anti-relapse treatment of HPE in women of reproductive age, after identifying changes characteristic of viral lesions in the morphological examination of endometrial tissue.

\section{Materials and Methods}

We examined 90 patients of the gynecological department of Ternopil Municipal City Hospital №2, who sought medical care during 2017-2019 for the hyperplastic processes of the endometrium in reproductive age. The age of women ranged from 18 to 49 years (average $34.52 \pm 2.51)$.

The criteria for inclusion of patients in the experiment have histologically confirmed the diagnosis of the hyperplastic endometrial process (with simple and complex atypical and atypical endometrial hyperplasia according to the classification of WHO endometrial pathology (2014)) [23]. These women were divided into two groups depending on the methods of treatment: I (main) - 30 women who received our proposed advanced complex therapy and II group - 30 women who received conventional treatment. Control - III group consisted of 30 patients of the same age category, healthy volunteers - volunteers, confirmed by aspiration "Pipelle" (Pipelle de Cornier) endometrial biopsy, followed by histological examination of the evacuated material.

The exclusion criteria were medical records of women with alimentary-constitutional obesity (BMI> 30.0), the presence of severe somatic or mental pathology in patients. 
Hysteroscopy was performed in the operating room under intravenous anesthesia on hard fiber optics company "KARL STORZ" from the 6th to the 11th day of the menstrual cycle (with a preserved menstrual cycle). After the complete removal of pathologically altered endometrial tissue, its histological examination was performed. The material was fixed in a buffered $10 \%$ formalin solution.

Pipelle biopsy was performed on days 19-23 MC using an aspiration probe. The aspiration probe was inserted into the uterine cavity in an assembled form to the bottom area, and the contents were aspirated with a piston, resulting in the effect of "suction" on the walls of the uterine cavity and through the existing perforation, material enters the probe. After performing 2-3 aspirations, the conductor was removed, and the probe was removed from the uterine cavity. The resulting material is placed in a vial with a $10 \%$ solution of neutral formalin.

Histological examination of endometrial tissue was performed according to the generally accepted method [25] on the basis of the department of the morphology of the interdepartmental educational and research laboratory of TNMU. I. Ya. Gorbachevsky, Ministry of Health of Ukraine.

The surgical material and endometrial tissue obtained by hysteroscopy and aspiration endometrial biopsy were subjected to morphological examination. Biopsy material was fixed in $10 \%$ neutral formalin. Further processing was performed according to the standard generally accepted unified method [8, 21]. Examination of histological specimens was performed using a Nikon Eclipse light microscope (Ci-E) using a digital video camera according to the software manufacturer's recommendations.

For electron microscopic examinations, pieces of endometrium were removed, fixed in $2.5 \%$ glutaraldehyde solution, and postfixed with $1 \%$ osmium tetraoxide solution on phosphate buffer. Further processing was performed according to the generally accepted method $[8,9]$. Ultrathin sections made on an ultramicrotome UMPT-7 were contrasted with uranyl acetate, lead citrate according to the Reynolds method, and studied under an electron microscope PEM$125 \mathrm{~K}$.

For detailed analysis and photo documentation, the image from the microscope was transferred to a computer monitor using a VISION Color CCD Camera and InterVideoWinDUR.

All diagnostic and therapeutic manipulations were performed after the written consent of the patients for examination and treatment in accordance with the protocol approved by the Bioethics Committee (№53 / 03.06.2019). Consent to surgical treatment was obtained before treatment.

The obtained data were processed using standard statistical methods using a personal computer HP PREMIER EXPERIENCE with Microsoft Word 2010; the graphics were built using Microsoft Excel. Statistical processing was performed by the program Statistics 10.

The study was conducted in compliance with Good Clinical Practice guidelines and the Declaration of Helsinki.

\section{Results and Discussion}

Hyperplastic processes of the endometrium - the most common pathology of the uterine body in women of childbearing age, which is manifested by uneven non-invasive proliferation of the endometrial glands. Compared with the proliferative endometrium, there is a violation of the glandular-stromal ratio, as well as lost functional and morphological function. 
By means of morphological research of endometrium, features of various types of HPE were revealed (Table 1).

Table 1. Comparative characteristics of the examined groups by types of hyperproliferative processes of the endometrium.

\begin{tabular}{l|l|l}
$\begin{array}{l}\text { Type of hyperproliferative processes } \\
\text { of the endometrium }\end{array}$ & And the main group $(\mathbf{n}=\mathbf{3 0})$ & II comparison group $(\mathbf{n}=\mathbf{3 0})$ \\
\hline $\begin{array}{l}\text { Simple atypical endometrial } \\
\text { hyperplasia }\end{array}$ & $10(33,33 \%)$ & $9(30 \%)$ \\
\hline $\begin{array}{l}\text { Complex atypical endometrial } \\
\text { hyperplasia }\end{array}$ & $9(30 \%)$ & $9(30 \%)$ \\
\hline $\begin{array}{l}\text { Simple atypical endometrial } \\
\text { hyperplasia }\end{array}$ & $6(20,00 \%)$ & $7(23,33 \%)$ \\
\hline $\begin{array}{l}\text { Complex atypical endometrial } \\
\text { hyperplasia }\end{array}$ & $5(16,67 \%)$ & $5(16,67 \%)$ \\
\hline
\end{tabular}

Note: $*$ - differences with control are significant $(\mathrm{p}<0,05)$.

Group III patients were diagnosed with endometrial structure, which corresponded to the relative norm (Fig. 1). No changes in the inherent hyperproliferative processes of the endometrium in the control group were detected.

Patients of the examined groups I and II did not differ statistically significantly in the number of patients in relation to a certain type of hyperplastic processes of the endometrium that is, they were homogeneous.

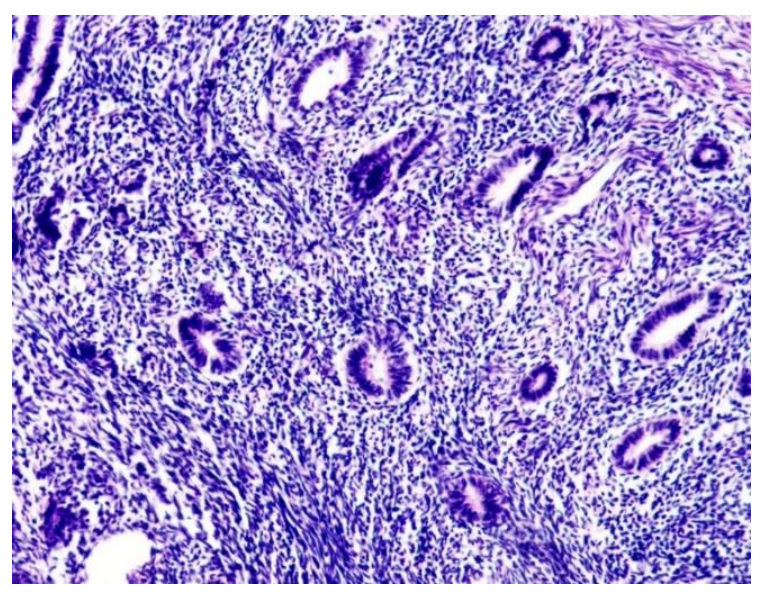

Figure 1. The structure of the endometrium at the relative norm. Hematoxylin and eosin staining. x 200.

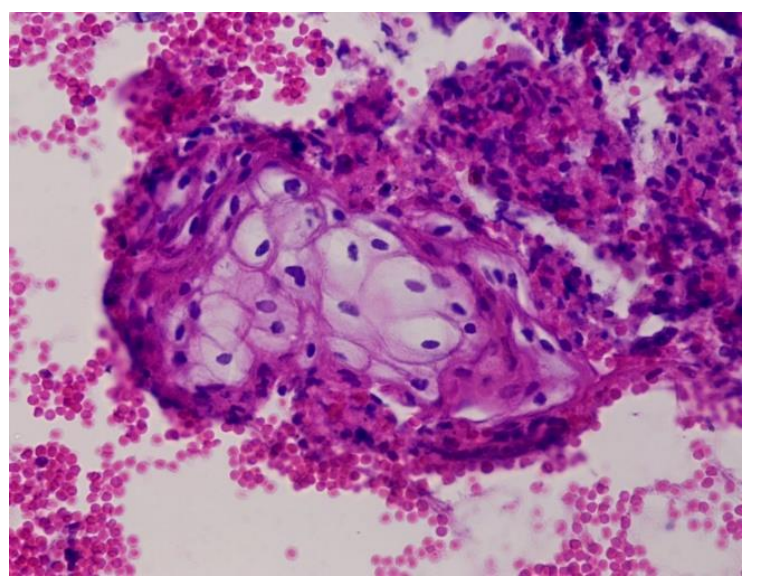

Figure 2. Cytoplasmic vacuolation of endometrial cells. Focal squamous cell metaplasia is a large foam cell among the endometrial glands. Hematoxylin and eosin staining. x 400 .

Histological examination of different types of endometrial hyperplasia in $74 \%$ of group I and $75 \%$ of group II cases $(p<0.05)$ revealed a squamous cell component (signs of metaplasia) 
(Fig. 2, 3). Due to the fact that cytoplasmic vacuolation of the epithelium is often characteristic of koilocytes, which are formed under the influence of the virus in the ectocervical epithelium, we studied various manifestations of endometrial hyperplasia and tried to establish the presence of viral elements in patients with various types of hyperplasia.

According to the scientific literature [25, 26], metaplastic processes are most often manifested in the altered endometrium, including hyperplasia, endometritis, atypical hyperplasia, or combined pathology. Papillary syncytial metaplasia is an exophytic proliferation of eosinophilic cells that form small syncytia or micropapillary processes on the surface of the endometrium or inside the glands and is often associated with glandular and stromal disorders. Eosinophilic and ciliated cell metaplasias are characterized by epithelial cells with a saturated dense eosinophilic cytoplasm or numerous cilia on the surface. Mucinous metaplasia reflects the presence of a pale, basophilic cytoplasm that is either vacuolated or granular. Squamous cell metaplasia consists of a significant mass of polygonal cells with dense eosinophilic cytoplasm and signs of keratinization. Secretory metaplasia is characterized by the presence of cells that contain sub- or supranuclear vacuoles resembling the early secretory endometrium.

The source of squamous cell epithelium in endometrial hyperplasia is unclear, but cells are more likely to arise as a result of metaplasia or through squamous cell differentiation of a common stem cell or glandular cell and may be stimulated by estrogen.

The defeat of epithelial cells by the virus in endometrial hyperplasia is possible in two ways - direct spread from the cervix, or infection through the blood.

Viruses are known to promote the development of tumors in both humans and animals, and HPV, for example, is known to frequently infect the ectocervical epithelium and is closely associated with the development of cervical cancer $[12,20]$. It became known that the virus is involved in the pathogenesis of endometrial hyperplasia [14, 29]. It is likely that it exists in epitheliocytes not only as a "passenger", but also as an etiological factor. In our studies, we observed a predominance of squamous cell metaplasia of the glandular epithelium from 39 to $61 \%$ of the studied cases. There was no significant difference between groups I and II, but it became known that it was in complex hyperplasia with atypia that the percentage reached the highest level, which is a precancerous condition (Fig. 2). In the control - III group, there were no typical cells that could indicate a viral infection of the endometrium.

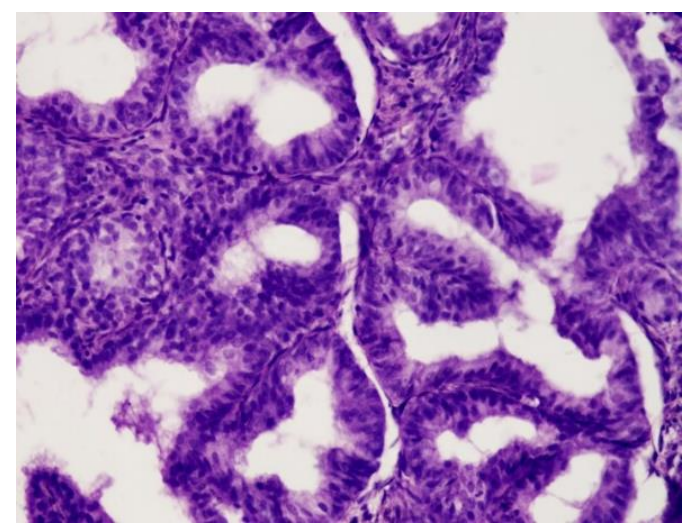

Figure 3. Complex endometrial hyperplasia with cellular atypia. Cytoplasmic vacuolation of individual epithelial cells. Hematoxylin and eosin staining. $x 400$.

Treatment is aimed at viral infection, as the cause of recurrence of hyperplastic endometrial processes in women of childbearing age began immediately after histological 
confirmation of the presence of benign HPE. Group II (comparative) patients received therapy according to the order of the Ministry of Health of Ukraine № 676 from 31.12.2004 - generally accepted treatment measures.

And the group (main) received therapy, according to the morphological study: to the usual treatment measures was added antiviral therapy: "acyclovir" at a dose of $200 \mathrm{mg} 5$ times a day for 10 days.

The effectiveness of treatment was monitored after 3,6, and 12 months using ultrasound control, pipelle-biopsy of the endometrium, and cases of re-hospitalization according to this pathology (Table 2). The pathomorphological examination performed after the pipette biopsy of the endometrium was to find specific "viral" cells.

Table 2. Analysis of the number of detected recurrences in the study groups.

\begin{tabular}{l|l|l|l|l} 
& \multicolumn{2}{|l}{ Group I (n= 30) } & \multicolumn{2}{l}{ Group II (n=30) } \\
\cline { 2 - 5 } & $\begin{array}{l}\text { Number of } \\
\text { women }\end{array}$ & $\%$ & $\begin{array}{l}\text { Number of } \\
\text { women }\end{array}$ & $\%$ \\
\hline Recurrence was detected by ultrasound & 3 & 10,00 & 6 & 20,00 \\
\hline $\begin{array}{l}\text { Recurrence was detected by pipette } \\
\text { biopsy }\end{array}$ & 0 & - & 3 & 16,67 \\
\hline $\begin{array}{l}\text { Recurrence was detected due to re- } \\
\text { hospitalization }\end{array}$ & 2 & 6,67 & 3 & 13,33 \\
\hline Total & 5 & 16,67 & 12 & 40,00
\end{tabular}

Note: $*$ - differences with control are significant $(\mathrm{p}<0,05)$.

The obtained data demonstrate a fairly high efficiency of the selected treatment and diagnostic algorithm. The recurrence rate of acyclovir in women with HPE is $-16.67 \%$, which is significantly $(\mathrm{p}<0.05)$ lower than in women who received traditional therapy $-40 \%$. The antiviral drug is effective in the treatment of HPE, which was confirmed by the results of the study. Therefore, our data substantiate the need to include antiviral therapy as pathogenetically justified in the treatment of patients with hyperplastic endometrial processes. It is obvious that the additional use of antiviral therapy in the complex treatment of HPE prevents recurrence of the disease and significantly increases treatment by 2.40 times.

\section{Conclusions}

The morphological change of an endometrium typical for defeat by a virus is revealed, speaks about the presence of infectious pathogens in the endometrium of patients with HPE, and it can be regarded as one of the possible triggers of development of hyperplastic processes.

Antiviral therapy in women of childbearing age, as a method of treatment to reduce the recurrence of HPE by using "acyclovir" $200 \mathrm{mg} 5 \mathrm{~g} / \mathrm{d}$ for 10 days showed 2.40 times greater effectiveness.

After analyzing the role of morphological signs of viral lesions in hyperplasia of the endometrium and the effectiveness of therapy indicates the need for additional research and justifies the search for and study of other effects on the endometrium to improve comprehensive drug therapy in patients with HPE. Detailed morphometry of various histotypes of HPE, with immunohistochemical research with the definition of a feature of expression of receptors in nuclei of cells of glands and stroma, and also the definition of expression of markers of proliferation (Ki-67) seems perspective. 


\section{Funding}

This research received no external funding.

\section{Acknowledgments}

This research has no acknowledgment.

\section{Conflicts of Interest}

The authors declare no conflict of interest.

\section{References}

1. Boichuk, A.V.; Shadrina, V.S.; Vereshchahina, T.V. Hyperplasia of endometrium - a modern systempathogenetic view on the problem (literature review): (literature review). Actual problems of pediatrics, obstetrics and gynecology 2019, 1, 67-72, https://doi.org/10.11603/24116-4944.2019.1.9906.

2. Gordts, S.; Grimbizis, G.; Campo, R. Symptoms and classification of uterine adenomyosis, including the place of hysteroscopy in diagnosis. Fertility and Sterility 2018, 109, 380-388, https://doi.org/10.1016/j.fertnstert.2018.01.006.

3. Lacheta, J. Uterine adenomyosis: Pathogenesis, diagnostics, symptomatology and treatment. Ceska gynekologie 2019, 84, 240-246.

4. Choi, E.J.; Cho, S.B.; Lee, S.R.; Lim, Y.M.; Jeong, K.; Moon, H.-S.; Chung, H. Comorbidity of gynecological and non-gynecological diseases with adenomyosis and endometriosis. Obstet Gynecol Sci 2017, 60, 579-586, https://doi.org/10.5468/ogs.2017.60.6.579.

5. Kulavsky, V.A.; Pushkarev, B.A.; Kulavsky, E.V.; Khusnutdinov, S.M.; Pushkarev, A.V. Pathology of the endometrium: (diagnostic and therapeutic aspects). Ufa: Healthcare publishing house of Bashkortostan, 2018; pp. 328.

6. Tingthanatikul, Y.; Lertvikool, S.; Rodratn, N.; Waiyaput, W.; Dittharot, K.; Sroyraya, M.; Sophonsritsuk, A. The effects of dienogest on macrophage and natural killer cells in adenomyosis: A randomized controlled study. Int. J. Fertil. Steril. 2018, 11, 279-286, https://doi.org/10.22074/ijfs.2018.5137.

7. Vovk, I.B.; Horban, N.Y.; Lysiana, T.A.; Netreba, N.I.; Ponomariova, N.H. The role of the inflammatory factor in the genesis of hyperplastic changes of endometrium in women of reproductive age. Actual Prob. Pediatr., Obstet. Gynecol. 2019, 1, 73-80, https://doi.org/10.11603/24116-4944.2019.1.10180.

8. Bagriy, M.M.; Dibrova, V.A.; Popadynets, O.G.; Grishchuk, I.M. Methods of morphological research: monograph. edited by Bagriya, M.M.; Vinnytsia, V.A.D. New book, 2016; pp. 238.

9. Chornenka, G.M.; Logach, M.V. Morphological features of endometrium in women of reproductive age: analysis of morphometric indicators. Achievements of Clinical and Experimental Medicine 2018, 146-150, https://doi.org/10.11603/1811-2471.2018.v0.i3.9275.

10. Vargas, M.V.; Huang, K.; Norwitz, E.; Miller, D.; Zelop, C.; Keefe, D. Endometriosis and adenomyosis. In: Evidence-based Obstetrics and Gynecology. John Wiley \& Sons, Ltd, 2019; pp. 75-87, https://doi.org/10.1002/9781119072980.ch8.

11. Adamane, S.A.; Mittal, N.; Teni, T.; Pawar, S.; Waghole, R.; Bal, M. Human Papillomavirus-Related Multiphenotypic Sinonasal Carcinoma with Unique HPV type 52 Association: A Case Report with Review of Literature. Head and Neck Pathology 2019, 13, 331-338, https://doi.org/doi:10.1007/s12105-018-09694.

12. Li, P.; Ma, J.; Zhang, X.; Guo, Y.; Liu, Y.; Li, X.; Zhao, D.; Wang, Z. Cervical small cell carcinoma frequently presented in multiple high risk HPV infection and often associated with other type of epithelial tumors. Diagnostic Pathology 2018, 13, https://doi.org/doi:10.1186/s13000-018-0709-9.

13. Tetikkurt, S.; Çelik, E.; Taş, H.; Cay, T.; Isık, S.; Usta, A.T. Coexistence of adenomyosis, adenocarcinoma, endometrial and myometrial lesions in resected uterine specimens. Mol Clin Oncol 2018, 9, 231-237, https://doi.org/doi:10.3892/mco.2018.1660.

14. Wu, Q.; Chu, Z.; Han, H.; Bai, S.; Wu, W.; Li, X.; Wei, S.; Yan, P. Primary squamous cell carcinoma of the endometrium in a woman of reproductive age: a rare case report. Journal of International Medical Research 2018, 46, 3417-3421, https://doi.org/10.1177/0300060518776579.

15. Dobrokhotova, Yu.E.; Yakubova, K.K. Microbiota of the reproductive tract and hyperplastic processes of the endometrium (literature review). RMJ "Medical Review", Gynecology 2018, 10, 14-16.

16. Moreno, I.; Cicinelli, E.; Garcia-Grau, I.; Gonzalez-Monfort, M.; Bau, D.; Vilella, F.; De Ziegler, D.; Resta, L.; Valbuena, D.; Simon, C. The diagnosis of chronic endometritis in infertile asymptomatic women: a comparative study of histology, microbial cultures, hysteroscopy, and molecular microbiology. American Journal of Obstetrics \& Gynecology 2018, 218, 601-602, https://doi.org/10.1016/j.ajog.2018.02.012. 
17. Horban, N.Ye; Vovk, I.B.; Lysiana. T.O.; Ponomariova, I.H.; Zhulkevych, I.V. Peculiarities of uterine cavity biocenosis in patients with different types of Endometrial Hyperproliferative Pathology. J. Med. Life 2019, 12, 266-270, https://doi.org/doi:10.25122/jml-2019-0074.

18. Baker, J.M.; Chase, D.M.; Herbst-Kralovetz, M.M. Uterine Microbiota: Residents, Tourists, or Invaders? 2018, 9, https://doi.org/doi:10.3389/fimmu.2018.00208.

19. Thompson, A.B.; Flowers, L.C. Human papillomavirus (HPV). In: Sexually transmitted infections in adolescence and young adulthood. Hussen, S. (eds). Springer, Cham, 2020; pp. 279-297, https://doi.org/10.1007/978-3-030-20491-4_18.

20. Upadhyaya, J.D.; Fitzpatrick, S.G.; Islam, M.N.; Bhattacharyya, I.; Cohen, D.M. A Retrospective 20-Year Analysis of Proliferative Verrucous Leukoplakia and Its Progression to Malignancy and Association with High-risk Human Papillomavirus. Head and Neck Pathology 2018, 12, 500-510, https://doi.org/doi:10.1007/s12105-018-0893-7.

21. Guidelines of the Royal College of Obstetricians and Gynecologists (RCOG) and the British Society of Gynecological Endoscopy (BSGE) dated February 2016 No. 67.

22. Younes, J.A.; Lievens, E.; Hummelen, R.; van der Westen, R.; Reid, G.; Petrova, M.I. Women and Their Microbes: The Unexpected Friendship. Trends in Microbiology 2018, 26, 16-32, https://doi.org/10.1016/j.tim.2017.07.008.

23. Kurman, R.J.; Carcangiu, M.L.; Herrington, C.S. World Health Organisation. Classification of tumours of the female reproductive organs. 4th Revised ed. International Agency for Research on Cancer 2014.

24. Honcharenko, G.Y. The role of steroid receptors in the pathogenesis of adenomyosis in the presence of concomitant endometrial pathology in postmenopause. Reports of morphology 2019, 1, 45-54, https://doi.org/10.31393/morphology-journal-2019-25(1)-07.

25. Rintala, M.; Vahlberg, T.; Salo, T.; Rautava, J. Proliferative verrucous leukoplakia and its tumor markers: Systematic review and meta-analysis. Head \& Neck 2019, 41, 1499-1507, https://doi.org/doi:10.1002/hed.25569.

26. Yang, F.; Li, H.; Qi, X.; Bian, C. Post-hysterectomy rare collision vulva tumor with long-term human papilloma virus infection composed of squamous cell carcinoma of the labia major and adenosquamous carcinoma of bartholin gland: A case report. Medicine 2019, 98, https://doi.org/10.1097/MD.0000000000017043.

27. Farhane, F.Z.; Alami, Z.; Bouhafa, T.; Elmazghi, A.; Hassouni, K. Primary squamous cell carcinoma of endometrium: case report and literature review. Pan Afr. Med. J. 2018, 4.

28. Ullah, F.; Javed, F.; Khan, A.N.; Kudus, M.H.A.; Jamila, N.; Minhaz, A.; Akil, H.M. Synthesis and surfacemodification of chitosan built nanohydrogel with antiviral and antimicrobial agent for controlled drug delivery. Biointerface Res. Appl. Chem., 2019, 9, 4439-4445. https://doi.org/10.33263/BRIAC96.439445.

29. Vasileva-Tonkova, E.; Grozdanov, P.; Nikolova, I.; Staneva, D.; Bosch, P.; Medel, S.; Grabchev, I. Evaluation of antimicrobial, biofilm inhibitory and cytotoxic activities of a new hiperbranched polymer modified with 1,8naphthalimide units. Biointerface Res. Appl. Chem., 2018, 8, 3053-3059. 